\title{
Regenerated Cellulose Membrane from Peanut Shell for Biodiesel Purification
}

\author{
Ana Maria S. Reis, ${ }^{a}$ Andressa T. Vieira, ${ }^{a}$ Allyson L. R. Santos, ${ }^{a}$ Marcos V. Ferreira, ${ }^{a}$ \\ Antônio C. F. Batista, ${ }^{a}$ Rosana M. N. Assunção, ${ }^{a}$ Guimes Rodrigues Filho, ${ }^{b}$ \\ Elaine A. M. Ribeiro ${ }^{c}$ and Anizio M. Faria ${ }^{\circledR} * a$
anstituto de Ciências Exatas e Naturais do Pontal, Universidade Federal de Uberlândia, 38304-402 Ituiutaba-MG, Brazil

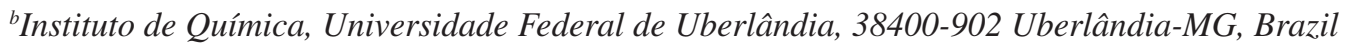 \\ ${ }^{c}$ Escola Técnica de Saúde, Universidade Federal de Uberlândia, 38400-732 Uberlândia-MG, Brazil
}

\begin{abstract}
Biodiesel purification by water washing has been proved to be an unattractive process from an economic and environmental point of view. In this work, we propose the use of regenerated cellulose membranes from peanut shell as an alternative in the biodiesel purification. The preparation of the membranes was optimized from a central composite design, resulting in dense and non-porous membranes. However, in contact with biodiesel, the membranes undergo expansion due to the retention of methanol, water, and glycerol molecules, allowing the permeation of fatty acid methyl esters. The filtered biodiesel presents quality parameters, such as total ester content of $98.3 \pm 1.4 \%$ and free glycerol content $<0.02 \%$, in agreement with the main regulatory agencies. The regenerated cellulose membranes from peanut shell are easily prepared, with high repeatability (relative standard deviation $(\mathrm{RSD})<1.8 \%$ ) and are presented as an economical and environmental solution for the biodiesel purification.
\end{abstract}

Keywords: peanut shell, cellulose membrane, biodiesel purification, GC-FID, glycerol

\section{Introduction}

The search for alternative energies, which are renewable and environmentally friendly, has been intense in recent decades. ${ }^{1,2}$ Reducing the use of fossil fuels and their high polluting power are among the main motivations for this search. Biodiesel can be considered an interesting energetic alternative to the fossil diesel since it is obtained from renewable sources and it does not release sulfur compounds during its burning in the engines. ${ }^{3-6}$

The most common method of obtaining biodiesel has been the transesterification reaction in which triglycerides of vegetable oils react with short chain alcohol (methanol or ethanol) in a molar ratio greater than 3:1 using a homogeneous basic catalyst $(\mathrm{KOH}$ or $\mathrm{NaOH})$, producing fatty acid esters. ${ }^{7,8}$ However, besides the mixture of fatty acid esters, characteristic of the raw material used, glycerol is also a co-product of the reaction. The largest fraction of the glycerol is removed from biodiesel after the reaction from the separation of phases by decanting, due to the

*e-mail: anizio@ufu.br difference in polarity and density of the products. ${ }^{9}$ On the other hand, after the decantation, a small residual fraction of free glycerol and acylglycerols remains in biodiesel, needing to be removed since it strongly affects biodiesel quality, reducing engine life and releasing toxic substances into the environment. ${ }^{10}$

The removal of glycerol residues from biodiesel for values within the limits established in the main international legislation can be obtained from a post-decantation purification step. This purification step is usually accomplished by washing the biodiesel with hot purified water, which is quite efficient due to the high solubility of the glycerol in water. However, the use of water in the biodiesel purification process results in a highly polluting liquid effluent with high chemical oxygen demand and high concentration of suspended solids. ${ }^{10,11}$ In addition to the environmental factor, cost increases and production time make biodiesel purification by the water washing method a disadvantageous and unattractive process as an alternative to fossil diesel.

Dry purification methods have been proposed to eliminate the use of water in the biodiesel production and 
all the disadvantages associated with its use..$^{12-15}$ One of the dry methods that have been promising in the purification of crude biodiesel is the membrane separation. ${ }^{13,16,17}$ In this process, the membrane acts as a barrier to the glycerol molecules, which are associated with other ones by hydrogen bonds increasing the particle size, while the molecules of the fatty acid esters pass the membrane pores, getting in the permeate and separating from the glycerol. ${ }^{18}$ Ceramic membranes ${ }^{19,20}$ and synthetic polymer ones ${ }^{21-23}$ have been the most exploited for biodiesel purification, despite the lower reproducibility and higher cost of the preparation process. Atadashi et al..$^{24}$ used a membrane filtration system to remove free glycerol and soap from crude biodiesel. The crude biodiesel was filtered through tubular membranes with $0.05 \mu \mathrm{m}$ pores, resulting in a retention coefficient of $97.5 \%$ free glycerol and $96.6 \%$ soap. ${ }^{24}$ Another study was conducted by Torres et al..$^{23}$ that prepared polymer membranes from poly(vinylidene fluoride) and poly(sulfone), evaluating the reduction of the glycerol content in soybean biodiesel. The poly(vinylidene fluoride) membrane achieved a $67 \%$ reduction of the glycerol and the poly(sulfone) membrane a reduction of $48 \%$. Organic polymer membranes, prepared from biomass residues, can be biodegradable, inexpensive and environmentally friendly alternatives for the purification of biodiesel, making whole biodiesel process as a viable alternative to fossil diesel.

Peanut shell is a residue from the agro-industry, obtained after the processing of peanuts, whose annual production reached levels of 45 million tons in 2018..$^{25}$ About $20 \%$ of the total mass of the peanut refers to its peel, which is usually discarded and subsequently burned. ${ }^{26}$ The main components of peanut shell are lignin, about $40 \%$, and polysaccharides (cellulose and hemicellulose), between 45-50\%. ${ }^{26,27}$ Therefore, the peanut shell presents itself as an interesting source of cellulose to produce membranes and subsequently be used for biodiesel purification. The cellulose can be extracted from the peanut shell and regenerated from a chemical or mechanical treatment. The regenerated cellulose can be obtained in three stages: dissolution, molding, and regeneration, which will eventually transform the cellulose into useful materials such as films, granules, fibers, membrane, etc. ${ }^{28-30}$ Regenerated cellulose membranes were produced from wheat straw, ${ }^{31}$ newspapers, ${ }^{32}$ cotton waste garments, ${ }^{29}$ among others, and all of them presented good mechanical properties.

In this work, we propose the extraction of cellulose from the peanut shell and its regeneration in the form of cellulose membranes for the purification of crude biodiesel obtained from the transesterification of soybean oil, removing the glycerol and alcohol residues. The characterization of the produced cellulose membrane and the membrane working mechanism in the process of separation of the glycerol from the soybean biodiesel methyl ester mixture are also presented.

\section{Experimental}

\section{Chemicals}

Peanut with shell was acquired in local greengrocers in the Triângulo Mineiro, MG, Brazil. Potassium hydroxide, acetic acid, sodium sulfate, bis(ethylenediamine)copper(II) hydroxide and hydrochloric acid were used for preparation of the cellulose membranes and were purchased from Hexis (São Paulo, Brazil). Glycerol PA was acquired from Hexis. Phosphorus pentoxide (99\%), methyl alcohol anhydrous (99.8\%), $n$-heptanol (98\%) and heptadecanoic acid methyl ester (analytical standard grade) were obtained from SigmaAldrich (São Paulo, Brazil). Sodium arsenite was acquired from Anidrol (Diadema, Brazil).

\section{Extraction of cellulose from the peanut shell}

The extraction of cellulose was performed according to Viera et $a l .^{33} 3.000 \mathrm{~g}$ of peanut shell was initially washed with distilled water to remove impurities. After that, the biomass was mixed with $100 \mathrm{~mL}$ of $\mathrm{KOH}$ solution at $24 \%(\mathrm{~m} / \mathrm{m})$ in an inert atmosphere, which was obtained by $\mathrm{N}_{2}$ flux into the solution for $10 \mathrm{~min}$. The mixture was placed in a water bath at $25^{\circ} \mathrm{C}$ for $2 \mathrm{~h}$ under constant stirring. The mixture was filtered through a sintered crucible and washed with $25 \mathrm{~mL}$ of a $24 \% \mathrm{KOH}$ solution, then with $25 \mathrm{~mL}$ of $10 \%(\mathrm{v} / \mathrm{v})$ aqueous acetic acid solution and finally with $100 \mathrm{~mL}$ of distilled water. The solid residue at the end of the filtration was washed with distilled water until the $\mathrm{pH}$ of the filtrate was neutral. Then it was washed with $50 \mathrm{~mL}$ of acetone and dried at $105{ }^{\circ} \mathrm{C}$ for $3 \mathrm{~h}$. After this period, the pulp was weighed to obtain a mass of $1.311 \pm 0.173 \mathrm{~g}$, which corresponded to $43.7 \pm 5.8 \%$ of the initial peanut shell mass. This value is very close to reported in the literature $^{34}$ for the cellulose content in the peanut shell, about $45.9 \%$. Cellulose was separated for later use in the preparation of membranes.

\section{Preparation and optimization of regenerated cellulose membranes}

The regenerated cellulose membranes were obtained from the cellulose extracted from the peanut shell. An amount of cellulose ( 0.75 to $1.05 \mathrm{~g}$ ) was added in $8.30 \mathrm{~mL}$ of ultrapure water and stirred at room temperature for 
$10 \mathrm{~min}$. Then, 15.0 to $26.7 \mathrm{~mL}$ of bis(ethylenediamine) copper(II) hydroxide (CUEN) was added, maintaining the mixture under magnetic stirring for $10 \mathrm{~min}$. The solution was purged with nitrogen gas for $5 \mathrm{~min}$, then returned to stirring for $1 \mathrm{~h}$. 0.20 to $0.60 \mathrm{~g}$ of sodium sulfate or silica gel was added to the solution under stirring. Then, $7 \mathrm{~mL}$ of the solution was spread on a Petri dish, standing it until the solution had completely dried at room temperature (ca. $27^{\circ} \mathrm{C}$ ) for $6 \mathrm{~h}$. After drying, the cellulose membrane was placed in a $1 \mathrm{~mol} \mathrm{~L}^{-1}$ of hydrochloric acid solution for $10 \mathrm{~min}$. The membranes were washed with distilled water and then left in acetone until use for the filtration process.

To optimize the preparation of regenerated cellulose membranes, an initial evaluation of variables (Table 1) that could affect biodiesel filtration was performed. Regenerated cellulose membranes were prepared under combinations of the levels of variables, following a $2^{5-2}$ fractional factorial design, and used in the filtration of soybean methyl biodiesel. The measured response for each experiment was the percentage of fatty acid methyl esters in the filtrates.

Table 1. Variables and levels studied in the optimization of the regenerated cellulose membrane preparation using a $2^{5-2}$ fractional factorial design

\begin{tabular}{lcc}
\hline \multirow{2}{*}{ Variable } & \multicolumn{2}{c}{ Level } \\
\cline { 2 - 3 } & - & + \\
\hline CUEN:cellulose ratio / (mL:g) & $2: 0.75$ & $4: 1.25$ \\
$\mathrm{~N}_{2}$ purge & no & yes \\
Stirring & magnetic & ultrasound \\
Porogenic agent & silica gel $(5-40 \mu \mathrm{m})$ & $\mathrm{Na}_{2} \mathrm{SO}_{4}$ \\
Porogenic agent mass / g & 0.200 & 0.600 \\
\hline
\end{tabular}

CUEN: bis(ethylenediamine)copper(II) hydroxide.

After the selection of variables, a study was carried out to optimize the most significant ones in the biodiesel purification process: the CUEN:cellulose ratio $\left(\mathrm{x}_{1}\right)$ and the amount of porogenic agent $\left(\mathrm{x}_{2}\right)$, by a composite central design (CCD). At this stage, the levels of the selected variables were expanded, as suggested by this type of experimental design. ${ }^{35}$ The matrix of experiments is presented in Table 2. Cellulose membrane preparations were performed combining all levels of the variables studied and the total ester content obtained after the filtration of soybean methyl biodiesel in each experiment was employed as the CCD response.

\section{Characterization of cellulose membranes}

After preparation and optimization, regenerated cellulose membranes were physico-chemically and morphologically characterized. The membrane surface and cross-sections,
Table 2. Matrix of experiments for the optimization of regenerated cellulose membrane preparation from peanut shell by central composite design

\begin{tabular}{lccccc}
\hline & \multicolumn{2}{c}{ Real value } & & \multicolumn{2}{c}{ Encoded value } \\
\cline { 2 - 3 } \cline { 5 - 6 } Experiment & $\begin{array}{c}\text { CUEN:cellulose } \\
\text { ratio / (mL:g) }\end{array}$ & $\begin{array}{c}\mathrm{Na}_{2} \mathrm{SO}_{4} \\
\text { mass / g }\end{array}$ & & $\mathrm{x}_{1}$ & $\mathrm{x}_{2}$ \\
\hline 1 & $16.7: 0.75$ & 0.200 & & - & - \\
2 & $25.0: 1.00$ & 0.200 & & + & - \\
3 & $16.7: 0.75$ & 0.600 & & - & + \\
4 & $25.0: 1.00$ & 0.600 & & + & + \\
5 & $20.9: 0.88$ & 0.400 & & 0 & 0 \\
6 & $20.9: 0.88$ & 0.400 & & 0 \\
7 & $20.9: 0.88$ & 0.400 & & 0 & 0 \\
8 & $15.0: 0.70$ & 0.400 & & -1.41 & 0 \\
9 & $26.7: 1.05$ & 0.400 & & +1.41 & 0 \\
10 & $20.9: 0.88$ & 0.120 & & -1.41 \\
11 & $20.9: 0.88$ & 0.680 & & 0 & +1.41 \\
\hline
\end{tabular}

CUEN: bis(ethylenediamine)copper(II) hydroxide; $x_{1}$ : CUEN:cellulose ratio; $\mathrm{x}_{2}$ : amount of porogenic agent.

before and after biodiesel filtration, were sputter-coated with gold and then examined with a TESCAN model Vega3 scanning electron microscope (Tokyo, Japan) at $20 \mathrm{kV}$. Fourier-transform infrared (FTIR) spectra of the little pieces of regenerated cellulose membranes were performed using attenuated total reflectance accessory in a Cary 630 FTIR infrared spectroscope (Agilent Technologies, Santa Clara, CA, USA). Thermal stability and thermogravimetric profiles of regenerated cellulose membranes from peanut shell were obtained by thermogravimetric analysis. Samples were heated from room temperature to $600{ }^{\circ} \mathrm{C}$, with $5{ }^{\circ} \mathrm{C} \mathrm{min}^{-1}$. Measurements were performed under $\mathrm{N}_{2}$ atmosphere in a TA Instruments thermogravimetric analyzer model TGA-55 (New Castle, DE, USA). The differential scanning calorimetry (DSC) experiments were done using a TA Instruments model DSC 25 equipment (New Castle, DE, USA) and aluminum pans, with the sample in little pieces. Heating rate was $10^{\circ} \mathrm{C} \mathrm{min}^{-1}$ and nitrogen flow was $50 \mathrm{~cm}^{3} \mathrm{~min}^{-1}$.

Water vapor flux (J) through the regenerated cellulose membranes was measured by the Payne's cup technique using $\mathrm{P}_{2} \mathrm{O}_{5}$ as a drying agent. The cellulose membrane, with the same diameter of the Payne's cup, had its thickness previously measured with a micrometer. Water was added to the cup and the regenerated cellulose membrane was placed onto the cup's support. The system was weighed and put into a desiccator and was subsequently weighed at every two minutes, which was enough for reaching the stationary state condition. Weight-loss was calculated according to equation $1 .^{36}$ 
$\mathrm{J}=\frac{\Delta \mathrm{m}}{\Delta \mathrm{tA}}$

where $\mathrm{J}$ is the water vapor flux, $\Delta \mathrm{m}$ is the quantity of permeate, $\mathrm{A}$ is the effective membrane area, and $\Delta \mathrm{t}$ is time to obtain the quantity of $\Delta \mathrm{m}$.

\section{Soybean biodiesel transesterification}

To evaluate the efficiency of regenerated cellulose membranes from peanut shells in biodiesel purification, biodiesel was prepared by the transesterification of soybean oil. Portions of soybean oil were subjected to a transesterification reaction with methanol, in the molar ratio of 1:6 (v/v) alcohol, using $1 \%(\mathrm{~m} / \mathrm{m})$ potassium hydroxide as the catalyst. Initially, the potassium methoxide was prepared by mixing $60.000 \mathrm{~g}$ of methyl alcohol and $3.000 \mathrm{~g}$ of potassium hydroxide under constant stirring until complete homogenization. Thereafter, the mixture was added to $300.000 \mathrm{~g}$ of soybean oil under constant stirring at $45{ }^{\circ} \mathrm{C}$ for $50 \mathrm{~min}$. After this period, the mixture was transferred to a separatory funnel, separating the biodiesel from the glycerol, after $50 \mathrm{~min}$ of rest.

The fraction of fatty acid methyl esters (crude biodiesel) was subjected to two additional purification processes: (i) distilled water washing and (ii) filtration through the regenerated cellulose membranes, using a vacuum filtration system.

\section{Biodiesel characterizations}

Samples of crude biodiesel and purified by water washing and filtration with regenerated cellulose membranes were submitted to the characterization of some properties such as total ester content, total and free glycerol content, acidity, kinematic viscosity, and specific gravity.

The total esters content was determined from the method EN 14103, ${ }^{37}$ using gas chromatography with flame ionization detection. $1 \mu \mathrm{L}$ of crude or purified biodiesel samples were injected into a gas chromatography-flame ionization detection (GC-FID) system from Thermo Scientific (San Jose, CA, USA), Focus GC model, using a Carbowax 20M chromatographic column $(30 \mathrm{~m} \times 0.25 \mathrm{~mm} \times 0.25 \mu \mathrm{m}$ film thickness $)$. GC conditions were split mode injection $(1: 10)$ at $250^{\circ} \mathrm{C}$; flame ionization detector temperature, $250{ }^{\circ} \mathrm{C}$; oven temperature at $190{ }^{\circ} \mathrm{C}$ holding for $7 \mathrm{~min} ; \mathrm{N}_{2}$ flow rate at $1.5 \mathrm{~mL} \mathrm{~min}^{-1}$. The free glycerol content in the crude, distilled water washed, and filtrated biodiesel samples were obtained by the official method Ca 14-56 from the American Oil Chemists' Society (AOCS) ${ }^{38}$ using an iodometric-periodic acid method. Free glycerol that remains after the decantation step was reacted with periodic acid. The resulting compound is titrated with normalized sodium arsenite solution using an aqueous starch $(1 \% \mathrm{~m} / \mathrm{v})$ indicator solution. The acidity index of the biodiesel samples was determined by the method EN 14104. ${ }^{39}$ The kinematic viscosity of the biodiesel samples was determined by the ASTM D445 method ${ }^{40}$ and the specific gravity of the biodiesel samples was determined by AOAC method $985.19 .{ }^{41}$

\section{Results and Discussion}

Initially, regenerated cellulose membranes were obtained from the spreading of the cellulose solution in a flat glass plate or a glass Petri dish. The main advantage of the Petri dish, with $10 \mathrm{~cm}$ in diameter, was to obtain circular membranes with $150 \mu \mathrm{m}$ thick (wet membrane) in the appropriate diameter for the filtration system (Figure S1, Supplementary Information (SI) section), without the need for any further processing. Also, the cellulose membranes prepared in the glass Petri dishes allowed a constant flow of biodiesel, with good permeability and with acceptable repeatability of total fatty acid methyl esters (FAME) in the permeate, relative standard deviation $(\mathrm{RSD})<4 \%$.

Optimization of the preparation of regenerated cellulose membranes by central composite design

In order to optimize the preparation of regenerated cellulose membranes from peanut shells, different preparation conditions were studied using a CCD. The membranes prepared were used in the filtration of crude soybean biodiesel and the permeate was analyzed by GC-FID for the determination of total esters content. According to EN 14103, ${ }^{37}$ the minimum total ester content must be greater than $96.5 \%$. Therefore, the objective of the optimization was to define the preparation conditions of the cellulose membranes that result in total ester contents in biodiesel above that required by the international biodiesel quality standards. ${ }^{38,42-44}$

First, a fractional factorial design was carried out to select the variables that most affect the performance of cellulose membranes in biodiesel filtration. Five variables at two levels each were combined to perform eight replicated experiments, as presented in Table S1 (SI section). From these experiments, it was observed that the variables that have the most significant effect in the preparation of cellulose membranes were CUEN:cellulose ratio and porogenic agent mass, which was defined as sodium sulfate (more significant than silica). These two variables were then 
optimized according to $\mathrm{CCD}$, performing 11 experiments (Table 2). The total ester content in the permeate obtained in each experiment was determined by GC-FID according to EN 14103. ${ }^{37}$ The results were used to construct a response surface from the CCD experiment matrix for the two variables studied (Figure 1).

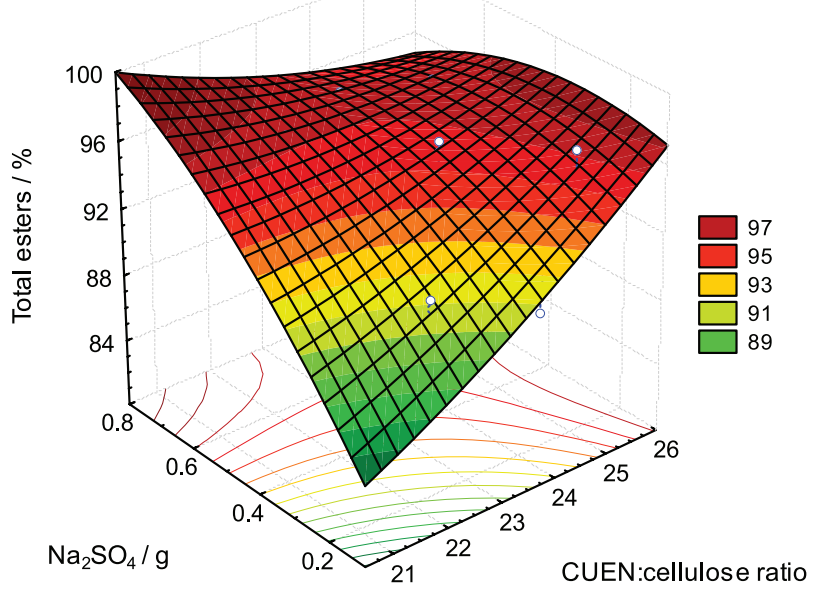

Figure 1. Response surface for the total ester content in the permeate after the filtration of soybean biodiesel by regenerated cellulose membranes prepared according to the central composite design.

In general, response dispersion within the investigated region may be considered very low (RSD $<1.8 \%$ ), as observed on the response surface (Figure 1). One experiment, in which the cellulose membrane was prepared with the lowest amount of sodium sulfate, was not able to filter the crude biodiesel. This implies that, for the regenerated cellulose membrane to act as a filter system, there is a need for the addition of a minimum amount of porogenic agent $\left(\mathrm{Na}_{2} \mathrm{SO}_{4}\right)$ in the membrane preparation guaranteeing permeation of the liquid by the membrane. The determination of the optimal conditions of the CUEN:cellulose ratio $\left(\mathrm{x}_{1}\right)$ and the mass of sodium sulfate $\left(\mathrm{x}_{2}\right)$ was obtained from the quadratic polynomial model generated by the response surface (equation 2). This model was submitted to the derivative of total ester content $\left(\mathrm{E}(\mathrm{z})\right.$ ) with respect to $\mathrm{x}_{1}$ and then with respect to $\mathrm{x}_{2}$. The optimized values were: CUEN:cellulose ratio as $18.2 \mathrm{~mL}: 0.80 \mathrm{~g}$ and $0.59 \mathrm{~g}$ of sodium sulfate mass. Under these conditions, according to the polynomial model obtained by the response surface, the total ester content in the filtered biodiesel would be $97.1 \%$.

$$
\mathrm{E}(\%)=96.86+1.24 \mathrm{x}_{1}+1.35 \mathrm{x}_{2}-1.11 \mathrm{x}_{2}^{2}-1.28 \mathrm{x}_{1} \mathrm{x}_{2}
$$

Table S2 in the SI section presents the analysis of variance (ANOVA) for total ester content in biodiesel purified by regenerated cellulose membranes. The $\mathrm{R}$-squared (coefficient of determination) indicated that the model explains $86.88 \%$ of the variability in total ester content of filtered biodiesel while the adjusted R-squared was $73.75 \%$.

Regenerated cellulose membranes from the peanut shells were prepared under optimized conditions and subjected to soybean biodiesel purification. Both the membranes and the filtered biodiesel were characterized to evaluate the action mechanism of the membranes and the efficiency of the biodiesel purification process.

\section{Characterization of regenerated cellulose membranes}

Cellulose membranes were evaluated for their morphology from scanning electron micrographs before and after biodiesel filtration (Figure 2). In these micrographs, it is possible to observe that before the filtration, the dry membranes appear as dense and nonporous membranes, despite the roughness aspect of their surface (Figures $2 \mathrm{a}$ and $2 \mathrm{~b}$ ). On the other hand, in the contact between the membrane and biodiesel, cellulose membranes expand, probably due to the formation of hydrogen bonds between hydroxyl groups of cellulose and water molecules and/or glycerol residues present in biodiesel, allowing the permeation of the FAME during the filtration. In the filtration of biodiesel with cellulose acetate and poly(ether sulfone) membranes, Alves et al. ${ }^{18}$ indicated that the molecules of water joined to glycerol and these larger molecules were unable to pass through the membrane pores, while the FAME molecules are permeated, reducing the amount of glycerol in biodiesel. It is important to mention that the morphology of the cellulose membranes is dependent on the lignocellulosic material employed, even though the membranes have been processed in a similar way. ${ }^{45}$ Sodium sulfate, as seen, needs to be present in a minimal amount in the membrane to allow filtration of biodiesel. This fact may be related to the formation of small cavities in the cellulose membrane due to the small solubilization of sodium sulfate in water molecules during the biodiesel filtration.

To evaluate the membrane conditions after the filtration process, thermogravimetric analysis (TGA) and DSC were performed. In the TGA, the change in the mass of the cellulose membrane as a function of temperature under a controlled heating rate is evaluated in order to identify thermal events associated with the volatilization of substances incorporated into the cellulose and the decomposition of the cellulose structure. In the DSC, the thermal events are associated with the change in the heat flow that affects the sample. This change can be associated 

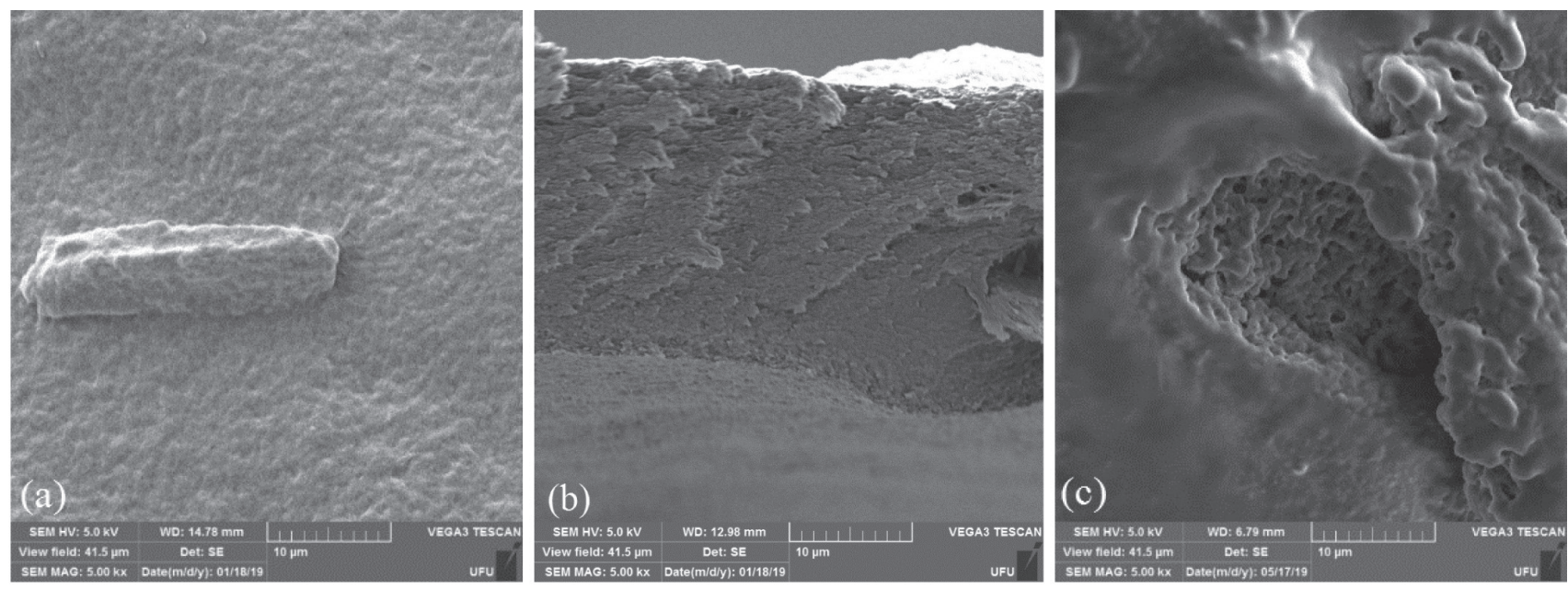

Figure 2. Micrographs of regenerated cellulose membranes from peanut shell (a, b) before and (c) after filtration.

to endothermic or exothermic processes that occur in the form of peaks in the DSC curves, being possible to observe physical and chemical processes of the cellulose and of substances incorporated to the cellulose.

The thermal stability of the cellulose membranes, before and after filtration, was evaluated by thermogravimetric analysis and the obtained TG curves are presented in Figure 3.

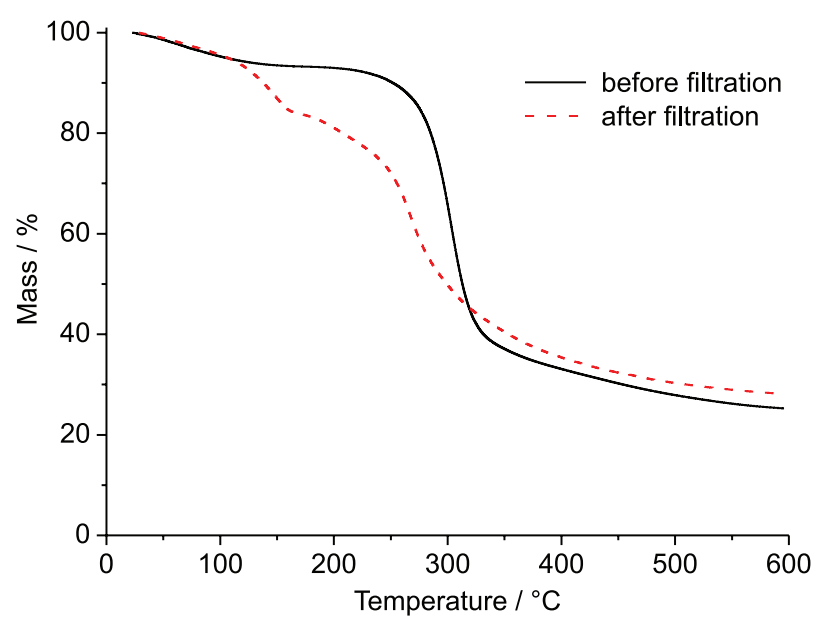

Figure 3. Thermogravimetric curves of regenerated cellulose membranes before and after biodiesel filtration.

The regenerated cellulose membrane presents a typical thermogravimetric profile expected for lignocellulosic materials, in which the first event highlights the desorption of adsorbed water in the cellulose structure due to its hydrophilicity and organizational structure. The membrane exhibits thermal stability up to about $200^{\circ} \mathrm{C}$, when the second thermal event related to thermal decomposition/degradation of the main chain of cellulose is started. The process occurs leaving a residue of $22 \%$ at $600^{\circ} \mathrm{C}$, which is related to the presence of sodium sulfate in its structure. After filtration, the membrane presents a high degree of swelling and an accumulation of biodiesel in its structure, changing the thermal stability of the membrane. Membrane swelling may be associated with the presence of methanol and glycerol residues forming hydrogen bonds with hydroxyl groups of the cellulose. The glycerol and FAME retained in the membrane after the filtration was removed up to $190{ }^{\circ} \mathrm{C}$, registering a thermal event before the degradation of the cellulose membrane.

Figure 4a shows the first scan DSC curves for the cellulose membrane before and after the biodiesel filtration. The cellulose membrane presents a single thermal event related to desorption of water adsorbed on the lignocellulosic material at $99.40{ }^{\circ} \mathrm{C}$. At higher temperatures, the membrane undergoes thermal decomposition as observed in the TG curves. For the cellulose membrane after filtration other events are observed, such as endothermic peaks at -55.45 and $-2.07{ }^{\circ} \mathrm{C}$ and an endothermic event at $112.41{ }^{\circ} \mathrm{C}$. The observed peaks are probably associated with the melting of the FAME present in the biodiesel, possible water desorption, and glycerol, respectively. The water desorption endothermic event for the cellulose membrane after biodiesel filtration has a different profile and temperature than that observed for the membrane before filtration. An endothermic event centered at $112.41{ }^{\circ} \mathrm{C}$ is observed for the membrane after filtration, the increase in temperature is indicative of a change in the pattern of the hydrogen bonds between methanol, water and cellulose due to the presence of biodiesel and small amounts of glycerol. In this case, the observed changes indicate higher polymer/water/methanol/glycerol interaction with increasing temperature for desorption of the bound water. These cause a significant change in the shape of 

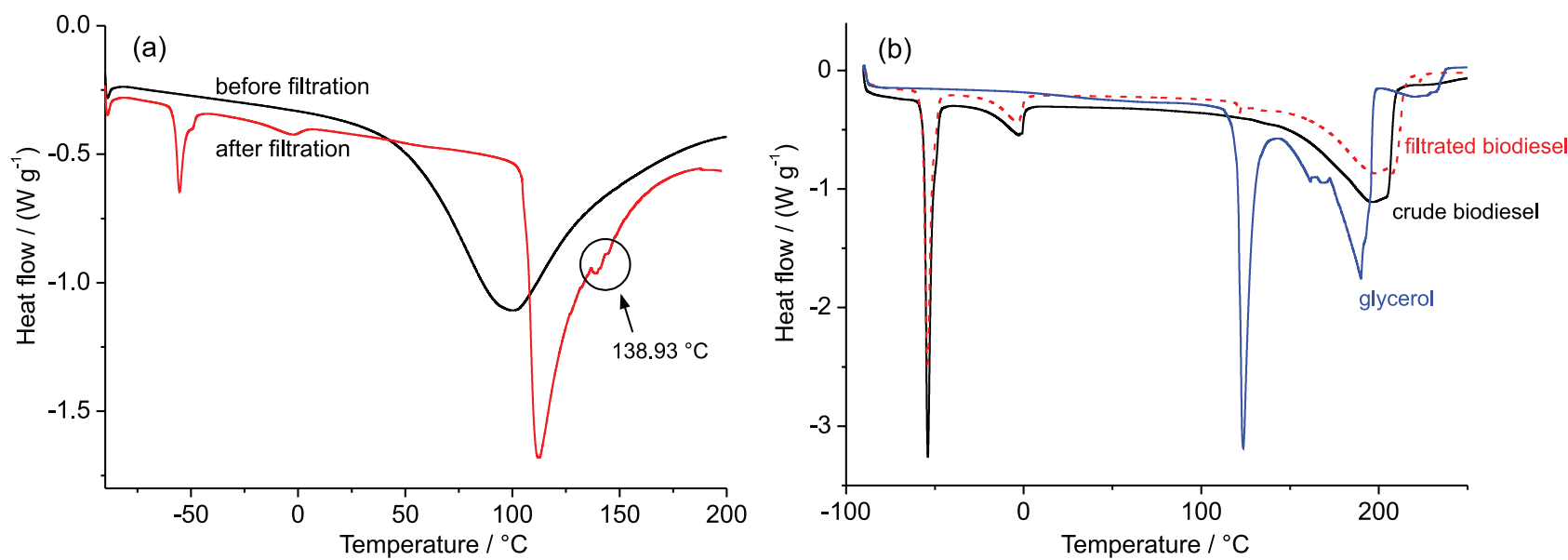

Figure 4. DSC curves of (a) regenerated cellulose membranes before and after biodiesel filtration; and (b) crude biodiesel, filtrated biodiesel, and glycerol.

the endothermic peak, which may be associated with the presence of methanol in surrounding of water and a small amount of glycerol in the polymer structure.

These observations are in accordance with DSC data for glycerol, crude biodiesel and filtered biodiesel shown in Figure $4 b$. The DSC curves present a profile with events associated with FAME melting at -53.51 and $-3.47{ }^{\circ} \mathrm{C}$ as recorded on the DSC curve of the membrane after filtration. The glycerol curve shows an endothermic event at $123.42{ }^{\circ} \mathrm{C}$. This data is possibly in agreement with that observed for the membrane after filtration which shows a low-intensity peak at $138.93{ }^{\circ} \mathrm{C}$ (Figure 4a) which may be associated with the presence of small quantities of glycerol and methanol.

The regenerated cellulose membranes were evaluated for their transport properties by measuring the water vapor flux through the Payne's cup technique. Membranes before and after the biodiesel filtration were submitted to the test. The membranes were initially measured for their diameter by a micrometer, and an expansion of $80 \%$ of the initial thickness of the cellulose membrane was observed after the biodiesel filtration. This expansion allowed the water vapor flux through the cellulose membrane to increase about 6.5 times as compared to the original membrane prior to filtration (Table 3). As seen, the cellulose membrane before filtration appears as dense and non-porous, but the contact with methanol, water or glycerol, expands its structure, allowing the permeation of biodiesel. This hypothesis is confirmed by the water vapor flux.
Regenerated cellulose membranes produced in this work were used for biodiesel purification by the vacuum-driven process. To evaluate the efficiency of the sample filtration and purification process, factors such as the effective membrane surface area and the expected effective volume after sample processing are important information. Regenerated cellulose membranes were evaluated for their maximum biodiesel filtration capacity. Membranes with a superficial area of $15.90 \mathrm{~cm}^{2}$ presented an average capacity to filter up to $200 \mathrm{~mL}$ of biodiesel, maintaining the total ester content of more than $96.5 \%$. In a test carried out to filter larger volumes of crude biodiesel, the sample shows a decrease in total ester content and an increase in glycerol content, indicating a decrease in sample purification capacity for crude biodiesel when volumes were greater than $200 \mathrm{~mL}$. In the filtration of crude biodiesel volumes greater than $400 \mathrm{~mL}$ a clear decrease in the filtrate volume was observed, indicating membrane fouling.

Regenerated cellulose membranes showed efficiency in the purification of crude biodiesel up to $200 \mathrm{~mL}$ of sample and durability for the point of view of filtration process up to $400 \mathrm{~mL}$ of crude biodiesel. The water permeability (in $\mathrm{cm}^{2} \mathrm{~s}^{-1}$ ) of cellulose membrane at $25^{\circ} \mathrm{C}$ was measured before and after filtration of soybean methyl biodiesel with values of $1.20 \times 10^{-5}$ and $7.83 \times 10^{-5} \mathrm{~cm}^{2} \mathrm{~s}^{-1}$, respectively. These values indicate that cellulose membranes, before and after filtration, have high permeability compared to those of several other membranes in literature. ${ }^{46}$

Table 3. Water vapor flux in the regenerated cellulose membranes, before and after biodiesel filtration

\begin{tabular}{lccc}
\hline Material & Diameter $/ \mathrm{cm}$ & Thickness $/ \mu \mathrm{m}$ & $\mathrm{J} /\left(\mathrm{g} \mathrm{s}^{-1} \mathrm{~cm}^{-2} \mu \mathrm{m}\right)$ \\
\hline Cellulose membrane before filtration & 3.1 & 51 & $2.76 \times 10^{-6}$ \\
Cellulose membrane after filtration & 3.1 & 91 & $1.81 \times 10^{-5}$ \\
\hline
\end{tabular}

J: water vapor flux. 


\section{Characterization of crude and purified biodiesel}

The cellulose membranes prepared under optimized conditions were used in the filtration of soybean biodiesel. The biodiesel was subjected to different characterization procedures to evaluate its quality after the filtration by regenerated cellulose membranes from the peanut shell. For the purposes of comparison, a portion of the same biodiesel was also purified by washing with distilled water and subjected to the same procedures to evaluate the quality of biodiesel. Crude biodiesel (without purification) was also characterized.

The chromatographic profile and the FAME composition of the biodiesel filtered by the regenerated cellulose membranes were obtained by GC-FID and are presented in Figure 5. The soybean biodiesel chromatogram shows the peaks referring to the methyl palmitate (C16:O), methyl stearate (C18:0), methyl oleate (C18:1), methyl linoleate (C18:2) and methyl linolenate (C18:3), the profile of which is in accordance with soybean biodiesel usually registered in the literature. ${ }^{47}$ In addition, the total ester content in biodiesel was $98.3 \%$, indicating that it is above

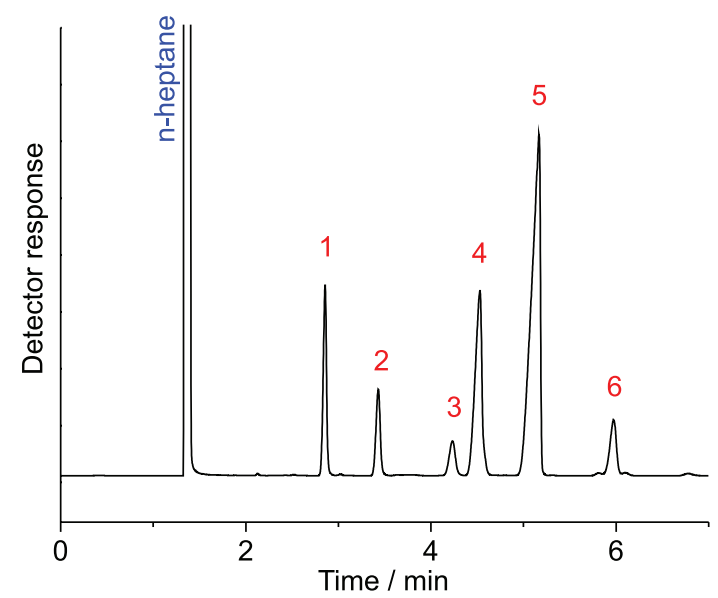

Figure 5. Chromatogram of the separation of fatty acid methyl esters in soybean biodiesel, filtered through the regenerated cellulose membranes from peanut shell. GC conditions: oven isotherm at $190{ }^{\circ} \mathrm{C}(7 \mathrm{~min})$; split injection $(1: 10)$ at $250{ }^{\circ} \mathrm{C}$; FID at $250{ }^{\circ} \mathrm{C} ; \mathrm{N}_{2}$ flow rate at $1.5 \mathrm{~mL} \mathrm{~min}^{-1}$; column Carbowax 20M $(30 \mathrm{~m} \times 0.25 \mathrm{~mm} \times 0.25 \mu \mathrm{m})$. Peak identification: 1: C16:0; 2: methyl heptadecanoate (internal standard); 3: C18:0; 4: C18:1; 5: C18:2; 6: C18:3. the minimum limit recommended by the main regulatory agencies $^{37}$ for the quality of biodiesel (>96.5\%), as well as close to the value estimated by the mathematical model determined by the CCD, which was $99.5 \%$.

The free glycerol content, acidity index, kinematic viscosity and specific gravity of biodiesel were also determined in biodiesel filtered by regenerated cellulose membranes and compared to those obtained in crude biodiesel and biodiesel washed with distilled water. Table 4 presents these results.

As can be seen in Table 4, all parameters measured in biodiesel filtered by regenerated cellulose membranes are within the limits established by the main international legislation, ${ }^{42}$ indicating that the filtration process is an efficient alternative to the washing of biodiesel with distilled water. Regenerated cellulose membranes were able to reduce glycerol residues in biodiesel by $72.7 \%$. Moreover, the free glycerol content in the filtered biodiesel was lower than that of the washed biodiesel, showing that in the membrane filtration process glycerol tends to be trapped in the regenerated cellulose membrane, probably through the interaction of the glycerol molecule with the hydroxyl groups of cellulose, reducing its content in biodiesel to levels within the recommended, which did not happen with biodiesel washed with hot water.

\section{Conclusions}

In this work, it was possible to optimize the preparation of regenerated cellulose membranes from the peanut shell and to use them as filtration systems for biodiesel purification. The regenerated cellulose membranes retain residual glycerol molecules present in biodiesel after the decanting process, reducing their levels within the limits established by the main international regulatory agencies of biodiesel quality. No characteristics measured in filtered biodiesel were inferior to those obtained by the conventional method by washing biodiesel with distilled water. In addition to the relatively simple preparation, regenerated cellulose membranes have also been shown to be highly reproducible and despite a non-porous and dense

Table 4. Physicochemical parameters of biodiesel filtered by the regenerated cellulose membranes, biodiesel washed with distilled water and crude biodiesel (without purification)

\begin{tabular}{lcccc}
\hline Physicochemical parameter & Crude biodiesel & Filtered biodiesel & Washed biodiesel & Reference $^{42}$ \\
\hline Total ester content / \% & 89.9 & 98.3 & 98.0 & 96.5 \\
Free glycerol / \% & 0.044 & 0.012 & 0.026 & 0.020 \\
Specific gravity / $\left(\mathrm{g} \mathrm{cm}^{-3}\right)$ & 0.885 & 0.888 & 0.884 & $0.850-0.900$ \\
Cinematic viscosity / cSt & 4.0 & 4.4 & 4.2 & $3.0-6.0$ \\
Acidic index / $\left(\mathrm{mg}_{\text {Кон }} \mathrm{g}^{-1}\right)$ & 0.12 & 0.12 & 0.24 & $<0.50$ \\
\hline
\end{tabular}


structure when dried, the membranes expand in contact with biodiesel, allowing the filtration of fatty acid methyl esters.

Compared to other filtration systems proposed for the purification of biodiesel, regenerated cellulose membranes from the peanut shells present the environmental and economic advantages due to the reuse of biomass residues, which are usually eliminated by burning.

\section{Supplementary Information}

Supplementary information (image of the regenerated cellulose membrane, total ester content in the biodiesel filtered by regenerated cellulose membranes according to the fractional factorial design experiments and analysis of variance obtained from the central composite design) is available free of charge at http://jbcs.sbq.org.br as PDF file.

\section{Acknowledgments}

This work was supported by the Financiadora de Estudos e Projetos (grant numbers 01.11.0135.00 and 01.13.0371.00). The authors would like to acknowledge the Multiuser Laboratory of Chemistry Institute at the Universidade Federal de Uberlândia for providing the equipment and technical support for experiments involving electron microscopy.

\section{Author Contributions}

Ana Maria S. Reis was responsible for the data curation, formal analysis, investigation and writing original draft; Andressa T. Vieira for the investigation and data curation; Allyson L. R. Santos for the investigation and formal analysis; Marcos V. Ferreira for the investigation and formal analysis; Antônio C. F. Batista for the validation and methodology; Rosana M. N. Assunção for the validation, resources and methodology; Guimes Rodrigues Filho for the conceptualization and resources; Elaine A. M. Ribeiro for the conceptualization and project administration; Anizio M. Faria for the conceptualization, project administration, supervision, and writing-review and editing.

\section{References}

1. Panwar, N. L.; Kaushik, S. C.; Kothari, S.; Renewable Sustainable Energy Rev. 2011, 15, 1513.

2. Verma, P.; Sharma, M. P.; Renewable Sustainable Energy Rev. 2016, 62, 1063.

3. Mahmudul, H. M.; Hagos, F. Y.; Adam, A. A.; Ishak, W. F.; Alenezi, R.; Renewable Sustainable Energy Rev. 2017, 72, 497.
4. Leung, D. Y. C.; Wu, X.; Leung, M. K. H.; Appl. Energy 2010 , 87, 1083.

5. Abbaszaadeh, A.; Ghobadian, B.; Omidkhah, M. R.; Najafi, G.; Energy Convers. Manage. 2012, 63, 138.

6. Gerpen, J. V.; Fuel Process. Technol. 2005, 86, 1097.

7. Fukuda, H.; Kondo, A.; Noda, H.; J. Biosci. Bioeng. 2001, 92 , 405.

8. Musa, I. A.; Egypt. J. Pet. 2016, 25, 21.

9. Atadashi, I. M.; Aroua, M. K.; Aziz, A. R. A.; Sulaiman, N. M.; Appl. Energy 2011, 88, 4239.

10. Berrios, M.; Skelton, R. L.; Chem. Eng. J. 2008, 144, 459.

11. Chol, C. G.; Dhabhai, R.; Dalai, A. K.; Reaney, M.; Fuel Process. Technol. 2018, 178, 78.

12. Ott, L. S.; Riddell, M. M.; O’Neill, E. L.; Carini, G. S.; Fuel Process. Technol. 2018, 176, 1.

13. Abdellatif, F. H. H.; Babin, J.; Arnal-Herault, C.; David, L.; Jonquieres, A.; Carbohydr. Polym. 2018, 196, 176.

14. Squissato, A. L.; Fernandes, D. M.; Souza, R. M. F.; Cunha, R. R.; Serqueira, D. S.; Richter, E. M.; Pasquini, D.; Muñoz, R. A. A.; Cellulose 2015, 22, 1263.

15. Gomes, M. G.; Santos, D. Q.; Morais, L. C.; Pasquini, D.; Fuel 2015, 155, 1.

16. Atadashi, I. M.; Alexandria Eng. J. 2015, 54, 1265.

17. Noriega, M. A.; Narváez, P. C.; Habert, A. C.; Chem. Eng. Res. Des. 2018, 138, 32.

18. Alves, M. J.; Nascimento, S. M.; Pereira, I. G.; Martins, M. I.; Cardoso, V. L.; Reis, M.; Renewable Energy 2013, 58, 15.

19. Maghami, M.; Sandrameli, S. M.; Shamloo, M.; Heat Mass Transfer 2018, 54, 2683.

20. Hu, M. Z.; Bischoff, B. L.; Morales-Rodriguez, M. E.; Gray, K. A.; Davison, B. H.; Ind. Eng. Chem. Res. 2019, 58, 1114.

21. Rodrigues, N. E.; Torres, J. J.; Ochoa, N. A.; Marchese, J.; Pagliero, C.; Materia 2018, 23, DOI 10.1590/S1517707620180002.0417.

22. Yusefi, M. G.; Rahimpour, A.; Mehdipour, H.; Biofuels 2016, 7, 263.

23. Torres, J. J.; Rodriguez, N. E.; Arana, J. T.; Ochoa, N. A.; Marchese, J.; Pagliero, C.; J. Cleaner Prod. 2017, 141, 641.

24. Atadashi, I. M.; Aroua, M. K.; Aziz, A. R. A.; Sulaiman, N. M. N.; Egypt. J. Pet. 2015, 24, 383.

25. Rico, X.; Bullón, B.; Alonso, J. L.; Parajó, J. C.; Yáñez, R.; Carbohydr. Polym. 2018, 183, 21.

26. Bharthare, P.; Shrivastava, P.; Singh, P.; Ttiwari, A.; Int. J. Adv. Res. Appl. Chem. 2014, 2, 1, available at http://citeseerx.ist.psu. edu/viewdoc/download?doi=10.1.1.679.5101\&rep=rep1\&type $=$ pdf, accessed in November 2019.

27. Liu, J. J.; Cai, Z.; Liao, Y.; Zhao, L.; Moulin, J.; Hartmann, C.; J. Food Saf. 2019, 39, DOI 10.1111/jfs.12611.

28. Mohamed, M. A.; Salleh, W. N.; Jaafar, J.; Hir, Z. A. M.; Rosmi, M. S.; Mutalib, M. A.; Ismail, A. F.; Tanemura, M.; Carbohydr. Polym. 2016, 146, 166. 
29. Haule, L. V.; Carr, C. M.; Rigout, M. L.; J. Cleaner Prod. 2016, 112,4445 .

30. Phinichka, N.; Kaenthong, S.; J. Mater. Res. Technol. 2018, 7 , 55.

31. Chen, H. Z.; Wang, N.; Liu, L. Y.; J. Chem. Technol. Biotechnol. 2012, 87, 1634.

32. Mohamed, M. A.; Salleh, W. N.; Jaafar, J.; Ismail, A. F.; Mutalib, M. A.; Jamil, S. M.; J. Appl. Polym. Sci. 2015, 132, DOI 10.1002/app.42684.

33. Viera, R. G. P.; Rodrigues Filho, G.; Assunção, R. M. N.; Meireles, C. S.; Vieira, J. G.; Oliveira, G. S.; Carbohydr. Polym. 2007, 67, 182.

34. Brown, P.; Jefcoat, A.; Parrish, D.; Gill, S.; Graham, E.; Adv. Environ. Res. 2000, 4, 19.

35. Bezerra, M. A.; Santelli, R. E.; Oliveira, E. P.; Villar, L. S.; Escaleira, L. A.; Talanta 2008, 76, 965.

36. Rodrigues Filho, G.; Cruz, S. F.; Pasquini, D.; Cerqueira, D. A.; Prado, V. S.; Assunção, R. M. N.; J. Membr. Sci. 2000, 177, 225.

37. EN 14103: Fat and Oil Derivatives - Fatty Acid Methyl Esters (FAME) - Determination of Ester and Linolenic Acid Methyl Ester Contents; European Committee for Standardization, Brussels, 2001.

38. American Oil Chemists' Society (AOCS); AOCS Official Method Ca 14-56, Official Methods and Recommended Practices of the AOCS, $5^{\text {th }}$ ed.; AOCS, Illinois, USA, 1998.

39. EN 14104: Fat and Oil Derivatives - Fatty Acid Methyl Esters (FAME), Determination of Acid Value; European Committee for Standardization, Berlin, 2003.
40. ASTM D445: Standard Test Method for Kinematic Viscosity of Transparent and Opaque Liquids (and Calculation of Dynamic Viscosity); ASTM International, West Conshohocken, PA, 2006.

41. Association of Official Analytical Chemists (AOAC); AOAC Official Method 985.19: (Apparent) Weight per Unit Volume and Specific Gravity of Fats and Oils; AOAC International, Rockville, MD, USA, 1985.

42. Agência Nacional do Petróleo, Gás Natural e Biocombustíveis (ANP); Resolução No. 7, de 19 de março de 2008; Estabelece a Especificação para a Comercialização de Biodiesel que Poderá Ser Adicionado ao Óleo Diesel; Diário Oficial da União (DOU), Brasília, Brazil, 2008.

43. ASTM D6751: Standard Specification for Biodiesel Fuel Blend Stock (B100) for Middle Distillate Fuels; ASTM International, West Conshohocken, PA, USA, 2012.

44. EN 14214: Automotive Fuels - Fatty Acid Methyl Esters (FAME) for Diesel Engines - Requirements and Test Methods; European Committee for Standardization, Brussels, 2008.

45. Souza, E. E.; Vale, R. S.; Vieira, J. G.; Ribeiro, D. S.; Rodrigues Filho, G.; Marques, F. A.; Assunção, R. M. N.; Meireles, C. S.; Barud, H. S.; Quim. Nova 2015, 38, 202.

46. Geise, G. M.; Park, H. B.; Sagle, A. C.; Freeman, B. D.; McGrath, J. E.; J. Membr. Sci. 2011, 369, 130.

47. Sato, R. T.; Stroppa, P. H. F.; Silva, A. D.; Oliveira, M. A. L.; Quim. Nova 2016, 39, 352.

Submitted: July 31, 2019

Published online: December 2, 2019 